Article

\title{
Transformation of Sulfur during Co-Hydrothermal Carbonization of Coal Waste and Food Waste
}

\author{
Pretom Saha ${ }^{1}\left(\mathbb{D}\right.$, Nepu Saha ${ }^{2}$, Shanta Mazumder ${ }^{1}$ and M. Toufiq Reza ${ }^{2, *(\mathbb{D})}$ \\ 1 Department of Mechanical Engineering, Ohio University, Athens, OH 45701, USA; \\ ps332316@ohio.edu (P.S.); sm583116@ohio.edu (S.M.) \\ 2 Department of Biomedical and Chemical Engineering and Sciences, Florida Institute of Technology, \\ Melbourne, FL 32901, USA; nsaha2019@my.fit.edu \\ * Correspondence: treza@fit.edu; Tel.: +1-321-674-8578
}

check for updates

Citation: Saha, P.; Saha, N.;

Mazumder, S.; Reza, M.T.

Transformation of Sulfur during Co-Hydrothermal Carbonization of Coal Waste and Food Waste. Energies 2021, 14, 2271. https://doi.org/ $10.3390 /$ en14082271

Academic Editor: Dino Musmarra

Received: 16 March 2021

Accepted: 16 April 2021

Published: 18 April 2021

Publisher's Note: MDPI stays neutral with regard to jurisdictional claims in published maps and institutional affiliations.

Copyright: (c) 2021 by the authors. Licensee MDPI, Basel, Switzerland. This article is an open access article distributed under the terms and conditions of the Creative Commons Attribution (CC BY) license (https:// creativecommons.org/licenses/by/ $4.0 /)$.

\begin{abstract}
Co-hydrothermal carbonization (Co-HTC) is an emerging technology for processing multiple waste streams together to improve their fuel properties in the solid product, known as hydrochar, compared to the hydrothermal carbonization (HTC) of those individual streams. Sulfur is considered one of the most toxic contaminants in solid fuel and the combustion of this sulfur results in the emission of $\mathrm{SO}_{\mathrm{x}}$. It was reported in the literature that, besides the fuel properties, Co-HTC reduced the total sulfur content in the hydrochar phase significantly. However, the transformation of different forms of sulfur has not yet been studied. Therefore, this study investigated the transformation of different forms of sulfur under the Co-HTC treatment. In the study, the Co-HTC of food waste (FW) and two types of coal wastes (middle bottom (CW1) and 4 top (CW2)) were conducted at $180{ }^{\circ} \mathrm{C}$, $230{ }^{\circ} \mathrm{C}$ and $280{ }^{\circ} \mathrm{C}$ for $30 \mathrm{~min}$. Different forms of sulfur were measured by using elemental analysis (total sulfur), and a wet chemical method (sulfate sulfur and pyritic sulfur). The organic sulfur was measured by the difference method. The results showed that a maximum of $49 \%$ and $65 \%$ decrease in total sulfur was achieved for CW1FW and CW2FW, respectively, at $230{ }^{\circ} \mathrm{C}$. Similar to the total sulfur, the organic sulfur was also decreased about $85 \%$ and $75 \%$ for CW1FW and CW2FW, respectively. Based on these results, a sulfur transformation mechanism under Co-HTC treatment was proposed.
\end{abstract}

Keywords: hydrochar; toxic contaminants; sulfate sulfur; pyritic sulfur; organic sulfur

\section{Introduction}

Co-hydrothermal carbonization (Co-HTC) is a process where blended biomass or coal-biomass blend is treated at high temperature $\left(180-280{ }^{\circ} \mathrm{C}\right)$ and autogenous vapor pressure (10-64 bar) in the residual moisture. The Co-HTC process results in a carbon-rich solid, commonly known as hydrochar, which can be used as solid fuel [1-3]. Our previous studies showed that the Co-HTC treatment of food waste (FW) and coal waste (CW) blend at $180-280{ }^{\circ} \mathrm{C}$ for $30 \mathrm{~min}$ improved solid fuel properties compared to their individual hydrothermal carbonization (HTC) [1,3]. This synergistic effect was due to the generation of acidic solutions by dehydration and decarboxylation reactions during the hydrothermal carbonization of FW, which catalyzed the degradation of CW and resulted in lower hydrochar yields. The combustion behavior of the produced Co-HTC hydrochars showed higher burnout temperatures compared to hydrochars produced from individual feedstocks. This is significant, because the Co-HTC hydrochar showed combustion properties similar to coal. Furthermore, the techno-economic analysis of a scaled-up plant $(81,175 \mathrm{~kg} / \mathrm{h}$ solid handling capacity) was studied and the process was found to be economically feasible [4].

Besides fuel properties and the economic feasibility of the Co-HTC process, it was further observed that Co-HTC reduces sulfur content from solid coal waste [1,3]. The hypothesis postulated that mild acid resulting from the FW during Co-HTC enhances the sulfur removal from coal waste. There are three main forms of sulfur, namely, sulfate sulfur, pyritic sulfur, and organic sulfur, which can be found in coal as well as biomass $[5,6]$. 
The combination of these forms is known as total sulfur. In general, the presence of total sulfur in fuel results in the emission of a high amount of $\mathrm{SO}_{\mathrm{x}}$ during the combustion process [7]. Researchers have previously studied various methodologies for removing $\mathrm{SO}_{\mathrm{x}}$ and $\mathrm{NO}_{\mathrm{x}}$ from flue gas [8,9]. Additionally, in recent years, the removal of sulfur from solid fuel has received the attention of researchers [1,10]. For instance, Xu et al. [10] have investigated the effect of various chemical agents on the desulfurization of coal, where they found that chemical oxidation combined with acidic ionic liquid extraction can remove significant amounts of sulfur. Recently, Saba et al. [1] have observed that the Co-HTC of coal and miscanthus blends can reduce the total sulfur content by about $48 \%$, while only HTC treatment reduced it by about 35\%. Previously, Timpe et al. [11] observed a nearly $50 \%$ decrease in organic sulfur from coal during the hydrothermal treatment using water above the critical temperature and below critical pressure. Favas et al. [12] reported that a significant portion of total sulfur was extracted as sulfate in wastewater during a hydrothermal dewatering process of low-rank coal at $320^{\circ} \mathrm{C}$ for $30 \mathrm{~min}$. However, to the best of the authors' knowledge, no study has been reported about the fate of various sulfur in the Co-HTC-treated hydrochar. In-depth knowledge regarding the different forms of sulfur and their transformation during the Co-HTC process is necessary to ensure the effective use of this process for sulfur reduction.

Therefore, the goal of this study was to analyze the transformation of different sulfur forms during HTC- and Co-HTC-treated hydrochars. To achieve this objective, the hydrochars were produced from CW, FW, and their blends at three different temperatures between 180 and $280{ }^{\circ} \mathrm{C}$. Different forms of sulfur present in the hydrochars were determined using a wet chemical method. The evaluation of the sulfur transformation will provide detailed knowledge on the concentration of different sulfur forms, and their conversion during the Co-HTC process. This information will be influential in predicting sulfur emission during the combustion of this feedstock.

\section{Materials and Methods}

\subsection{Materials}

Two different types of CW materials were collected from Southeast Ohio. The samples were named middle bottom (CW1) and 4 top (CW2) depending on the location of the collection. On the other hand, FW was collected for the Central Food Facility of Ohio University.

Barium sulfate $\left(\mathrm{BaSO}_{4}\right)$, barium chloride, optima grade $12 \mathrm{~N}$ hydrochloric acid $(\mathrm{HCl})$, $10 \%(v / v)$ ammonium hydroxide, ethanol, reagent grade bromine water, certified ACS grade methyl orange, and ACS reagent grade silver nitrate were purchased from Fisher Scientific (Waltham, MA, USA). All of these chemicals were used for identifying the various form of sulfurs in the hydrochar.

\subsection{Methodology}

\subsubsection{Feedstocks Preprocessing}

Collected FW was crushed using a food processor (Cuisinart Elite 2.0 16-Cup Food Processor) and dried for $24 \mathrm{~h}$ in an oven at $105^{\circ} \mathrm{C}$. Both the $\mathrm{CW}$ and dried FW samples were sieved, and sample sizes between 0.25 and $0.60 \mathrm{~mm}$ were collected and stored in a Ziploc bag for Co-HTC.

\subsubsection{Co-HTC of FW and CW Blends}

All the Co-HTC experiments were conducted in a $600 \mathrm{~mL}$ Parr reactor at temperatures of $180^{\circ} \mathrm{C}, 230^{\circ} \mathrm{C}$ and $280{ }^{\circ} \mathrm{C}$ for $30 \mathrm{~min}$. All the experiments consisted of $1: 10$ dry feedstock to deionized water, where the feedstock consisted of $50 \mathrm{wt} . \% \mathrm{FW}$ and $50 \mathrm{wt} . \% \mathrm{CW}$. The reactor was heated at a constant heating rate $\left(3{ }^{\circ} \mathrm{C} / \mathrm{min}\right)$ until the set temperature and held at isothermal level for $30 \mathrm{~min}$. The reactor content was stirred at $180 \mathrm{rpm}$ throughout the experiment to ensure product homogeneity. At the end of the reaction time, the reactor was cooled down rapidly to room temperature by an ice-water bath. The solid product (hydrochar) was separated from the process liquid by using Whatman filter paper, Grade 
$41(20 \mu \mathrm{m})$, and dried at $105^{\circ} \mathrm{C}$ in an oven for $24 \mathrm{~h}$. The dried hydrochar product was stored in a desiccator for further analysis. The details of the Co-HTC experiments can be found elsewhere [3].

\subsubsection{Analyzing Sulfur Forms}

Total sulfur was determined through ultimate analysis of the produced hydrochar using a Flash 2000 Elemental Analyzer (Thermo Scientific, Waltham, MA, USA). A detailed method can be found elsewhere [13]. On the other hand, different sulfur forms (e.g., sulfate sulfur, pyritic sulfur, and organic sulfur) were analyzed using a wet chemical method (ASTM D-2492) [14]. In summary, about $2 \mathrm{~g}$ of hydrochar sample was taken to quantify various kinds of sulfur. First, $50 \mathrm{~mL}$ of dilute $\mathrm{HCl}(4.8 \mathrm{~N})$ was added slowly with the hydrochar samples following by a few drops of ethanol for facilitating the wetting process. This mixture was placed on a hotplate and boiled at $45^{\circ} \mathrm{C}$ for $30 \mathrm{~min}$. After that $30 \mathrm{~min}$ of boil-off, the sample was filtered out using a Type II, Class F filter paper. The filter paper was washed with deionized water to make sure there was no remaining $\mathrm{HCl}$ with it. This filter paper was further used for the calculation of pyritic sulfur content in the sample. The filtrate solution was used for the sulfate sulfur measurements. About $5 \mathrm{~mL}$ of bromine water was added into the filtrated solution followed by aqueous ammonium hydroxide until a slight excess was detected by using $\mathrm{pH}$ indicator paper. Finally, an additional $5 \mathrm{~mL}$ of bromine water was added to coagulate the ferric hydroxide. Precipitated ferric hydroxide was filtered out using a Type II, Class E filter paper. This filter paper was later used for the sulfate sulfur determination. Similar steps were followed without any hydrochar samples which were considered as control runs. These control runs were taken into account for determining the final concentrations of pyritic and sulfate sulfur contents in the samples. A detailed ASTM D-2492 method can be found elsewhere [14]. The organic sulfur was determined by the difference method where the pyritic and sulfate sulfur was subtracted from the total sulfur. All the investigations were carried out in duplicate.

\section{Results and Discussions}

Figure 1 shows the various forms of sulfur present in the raw coal waste samples (CW1 and CW2), HTC-derived hydrochar samples, and theoretically calculated CW and FW samples (i.e., theoretical CW1FW and theoretical CW2FW) in terms of hydrochar. The figure illustrates that the HTC process did not significantly affect any form of sulfur content in the CW1 and CW2. There was no sulfur content observed in the FW and their hydrochar [3]. The theoretical values in Figure 1 were calculated by summing up the $50 \%$ and $50 \%$ sulfur contents in the CW and FW hydrochars, respectively, at the corresponding temperatures.

This study assumed total sulfur to be a combination of three different sulfur forms-sulfate sulfur, pyritic sulfur, and organic sulfur. Figure 1 shows that the organic sulfur constituents were about $71 \%$ and $67 \%$ of the total sulfur present in raw CW1 and CW2, respectively. This high concentration of organic sulfur in CW1 and CW2 gradually decreased with the increase in HTC temperature. Wu et al. [15] observed similar phenomena during the hydrothermal dewatering of low-rank Xiaolongtan coal and concluded that the organic sulfur was released in the gaseous products. Researchers have reported a similar decrease in organic sulfur in the solid phase during hydrothermal carbonization of sewage sludge, which was possible because of the formation of $\mathrm{SO}_{2}$ in the gaseous phase and sulfate ions in the liquid phase $[16,17]$. However, sulfate sulfur, which constitutes less than $10 \%$ of total sulfur, increased with the HTC temperature in both the raw coal waste samples. Although the increment was slow at 180 , and $230^{\circ} \mathrm{C}$, the sulfate sulfur content increased significantly at $280^{\circ} \mathrm{C}$ and reached a maximum of 11.2 and $13.5 \mathrm{mg} / \mathrm{g}$ hydrochar for CW1 and CW2, respectively. The conversion of organic sulfur into sulfate sulfur could be the reason for this increase [15]. Wang et al. [18] observed a similar increase in sulfate sulfur while studying the transformation of sulfur impurities in lower rank coals. In the case of pyritic sulfur, the change in the concentration of pyritic sulfur was statistically 
insignificant with respect to the hydrothermal carbonization temperature. This finding is similar to the results reported by Wu et al. [15].

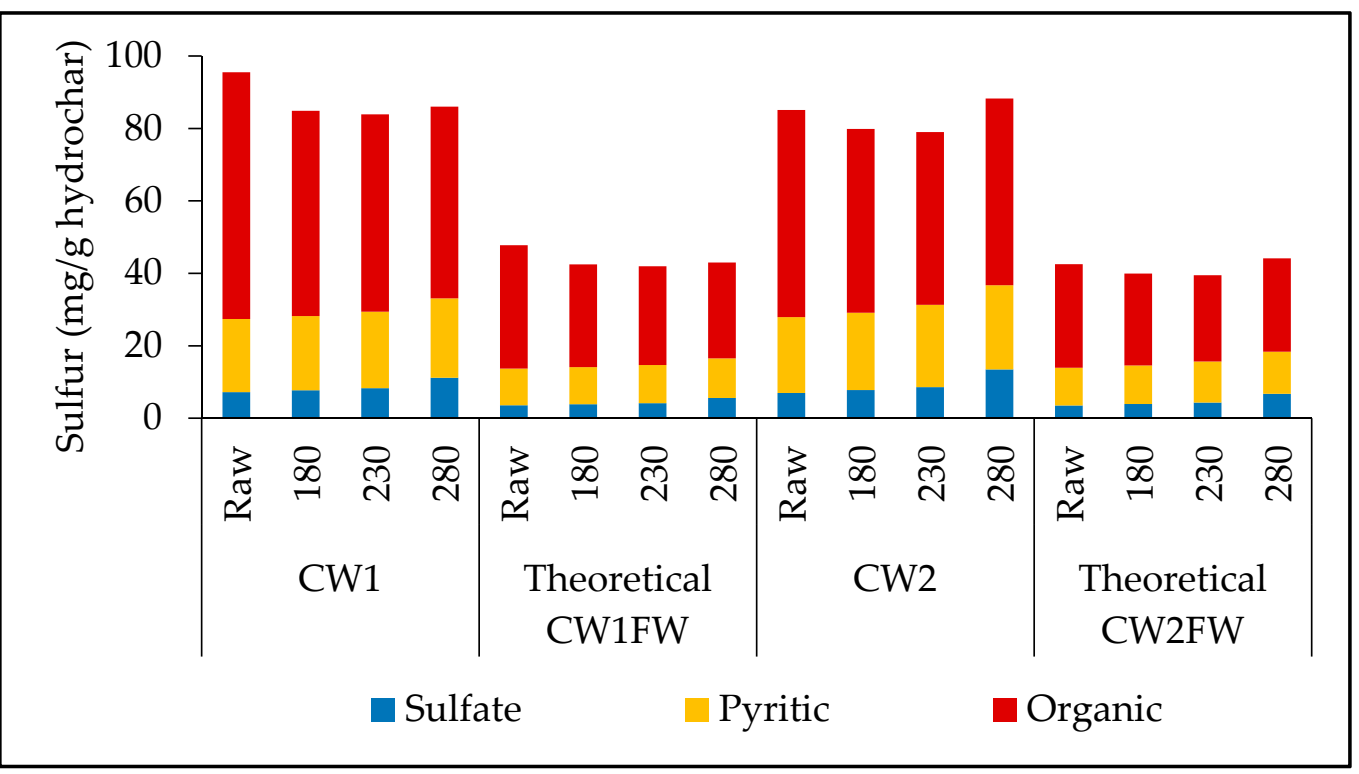

Figure 1. Change of different forms of sulfur in CW-derived hydrochar under various HTC temperatures and theoretically calculated values in CW and FW blended hydrochar at corresponding Co-HTC temperatures. "Raw" indicates the feedstock without any treatment. Note: there was no sulfur content observed in the FW feedstock and its hydrochar.

The Co-HTC results reported in Table 1 show a drastic decrease in total sulfur concentration in CW1FW and CW2FW compared to theoretical CW1FW and CW2FW. A maximum of $49 \%$ decrease in total sulfur content was achieved for CW1FW, while for CW2FW, the decrease was as high as $65 \%$ compared to their theoretical values at $230{ }^{\circ} \mathrm{C}$. Similarly, the concentration of different forms of sulfur also decreased up to $230^{\circ} \mathrm{C}$ compared to their theoretical concentrations. For instance, at $230{ }^{\circ} \mathrm{C}$, a maximum of $85 \%$ and $75 \%$ decrease in organic sulfur in CW1FW and CW2FW, respectively, was observed, compared to their theoretical values. In the meantime, the concentration of sulfate sulfur and pyritic sulfur also decreased significantly during the Co-HTC process. The dehydration and decarboxylation reaction during the HTC of FW produced a mild acidic condition, which leached these different forms of sulfur from the coal waste samples $[19,20]$. Furthermore, at the highest Co-HTC temperature $\left(280^{\circ} \mathrm{C}\right)$, an opposite behavior was observed while the sulfur content started to deposit on the hydrochars due to the excessive condensation and polymerization reactions, which resulted in the regain of sulfur content on the hydrochar $[15,17]$.

Table 1. Change of different forms of sulfur content with Co-HTC of FW and CW at various Co-HTC temperatures.

\begin{tabular}{cccccc}
\hline Sample Name & $\begin{array}{c}\text { Co-HTC } \\
\text { Temperature }\left({ }^{\circ} \mathbf{C}\right)\end{array}$ & $\begin{array}{c}\text { Sulfate Sulfur } \\
(\mathbf{m g} / \mathbf{g} \text { Hydrochar) }\end{array}$ & $\begin{array}{c}\text { Pyritic Sulfur } \\
\text { (mg/g Hydrochar) }\end{array}$ & $\begin{array}{c}\text { Organic Sulfur } \\
\text { (mg/g Hydrochar) }\end{array}$ & $\begin{array}{c}\text { Total Sulfur } \\
\text { (mg/g Hydrochar) }\end{array}$ \\
\hline \multirow{3}{*}{ CW1FW } & 180 & $5.4 \pm 0.5$ & $9.8 \pm 0.8$ & $25.0 \pm 1.7$ & $40.2 \pm 1.1$ \\
& 230 & $6.9 \pm 1.1$ & $10.4 \pm 0.6$ & $4.1 \pm 1.1$ & $21.4 \pm 1.0$ \\
\hline \multirow{2}{*}{ CW2FW } & 280 & $8.1 \pm 1.3$ & $11.4 \pm 0.7$ & $12.6 \pm 1.9$ & $32.1 \pm 1.5$ \\
& 180 & $6.1 \pm 0.6$ & $7.9 \pm 1.2$ & $20.2 \pm 1.5$ & $34.2 \pm 1.1$ \\
& 230 & $3.4 \pm 1.2$ & $4.6 \pm 1.2$ & $5.9 \pm 1.4$ & $13.9 \pm 1.6$ \\
\hline
\end{tabular}

On the other hand, the concentration of sulfate sulfur in total sulfur increased with the increase in Co-HTC temperature and reached their maximum concentration of $32 \%$ and $24 \%$ for CW1FW and CW2FW, respectively, at $230{ }^{\circ} \mathrm{C}$. This can result from the pre- 
cipitation formed by sulfate and metal ions, as described in the sulfur transformation mechanism by Wu et al. [15]. The decomposition of organic sulfur could be another reason for this increase [21]. The pyritic sulfur concentration also reached a peak value at $230^{\circ} \mathrm{C}$. Wang et al. [18] believed that the breaking of sulfur bonds in sulfides is responsible for the increase in pyritic sulfur. The concentration of organic sulfur showed an opposite trend compared to other forms and reached minimum values of 19 and $42 \%$ of the total sulfur for CW1FW and CW2FW, respectively, when the Co-HTC temperature was increased from 180 to $230{ }^{\circ} \mathrm{C}$. The decomposition of the organic sulfur functional group during high-temperature Co-HTC could be a possible reason for this decline [22,23]. However, the organic sulfur concentration in total sulfur increased while the sulfate and pyritic sulfur decreased when the temperature was raised to $280^{\circ} \mathrm{C}$. This can happen due to the increase in thiophene or sulphones (a form of organic sulfur) during polycondensation [24]. This decrease in organic sulfur concentration and increase in the concentration of other sulfur forms during the Co-HTC process may indicate the possibility of a decrease in $\mathrm{SO}_{2}$ emission and an increase in $\mathrm{H}_{2} \mathrm{~S}$ emission [18]. It is known that most of the $\mathrm{SO}_{2}$ emissions originated from the sulphones, while $\mathrm{H}_{2} \mathrm{~S}$ emissions originated from aliphatic and pyritic sulfur during the combustion of sulfur-containing solid fuel [25-27].

Although the above results clearly show a synergistic effect of Co-HTC on sulfur transformation per hydrochar basis, this trend could be changed per feed basis due to the low hydrochar mass yield of FW. The mass of FW and CW under various HTC temperatures can be found in our earlier study [3]. These mass yields were further used to calculate the absolute values of various forms of sulfur per feed basis, which is shown in Figure 2. The FW had no sulfur content; therefore, all the values in Figure 2 were presented per coal feed basis. In summary, a similar trend of sulfur transformation was observed when FW was co-treated with both CW1 and CW2. For instance, all forms of sulfur content reduced up to a Co-HTC temperature of $230^{\circ} \mathrm{C}$ following by an increasing tread at $280^{\circ} \mathrm{C}$, which could be due to the sulfur precipitation mentioned in the earlier section. The total sulfur content in the CW1 hydrochar reduced by about $15 \%$ compared to the coal feed. However, with the Co-HTC with the FW, the theoretical reduction was about $45 \%$. However, the experimental reduction was significantly higher (to some extent, it was 51\%) than the theoretical values. A similar phenomenon was observed for CW2- and FW-derived hydrochar, where the experimental reduction was up to $67 \%$ higher than the theoretical reduction at $230{ }^{\circ} \mathrm{C}$. Similar to the total sulfur, organic and pyritic sulfur showed higher reductions compared to the theoretical values. However, the sulfate sulfur showed an opposite behavior. The experimental sulfate sulfur was higher than the theoretical values. All of these phenomena indicated that the Co-HTC of FW and CW has a synergistic effect on all forms of sulfur, no matter whether they are presented in the basis of product (hydrochar) or feed (coal).

Based on the above observation, a sulfur transformation mechanism could be further developed for the Co-HTC treatment of CW and FW. The proposed mechanism is shown in Figure 3. There was no sulfur in FW; therefore, all the sulfur was in coal waste. First, organic sulfur from the solid phase is eluted to the gaseous phase by producing $\mathrm{H}_{2} \mathrm{~S}$ and $\mathrm{SO}_{2}$. The reaction experiences high pressure (10-64 bar) during the Co-HTC process; therefore, a fraction of $\mathrm{SO}_{2}$ will be solubilized in the liquid process, because the solubility of $\mathrm{SO}_{2}$ is significantly higher than $\mathrm{H}_{2} \mathrm{~S}$ [28]. The solubilized $\mathrm{SO}_{2}$ could further react with the oxygen-containing acidic groups (e.g., $\mathrm{COOH}, \mathrm{C}=\mathrm{O}$, etc.), and therefore form sulfate ions $\left(\mathrm{SO}_{4}{ }^{2-}\right)$. These sulfate ions will then be reacted with iron from the hydrochar surface and form sulfate sulfur (i.e., $\left.\mathrm{FeSO}_{4}, \mathrm{Fe}_{2}\left(\mathrm{SO}_{4}\right)_{3}\right)$. Hydrothermal carbonization of biomass produces an acidic solution; therefore, the presence of oxygen-containing acidic groups was expected [29]. The acidity of the solution increases with the increase in HTC temperature, resulting in an increase in sulfate sulfur. The pyritic sulfur was observed as the most stable component under Co-HTC treatment, while similar phenomena were observed by Wu et al. [15] for coal under the hydrothermal process. 

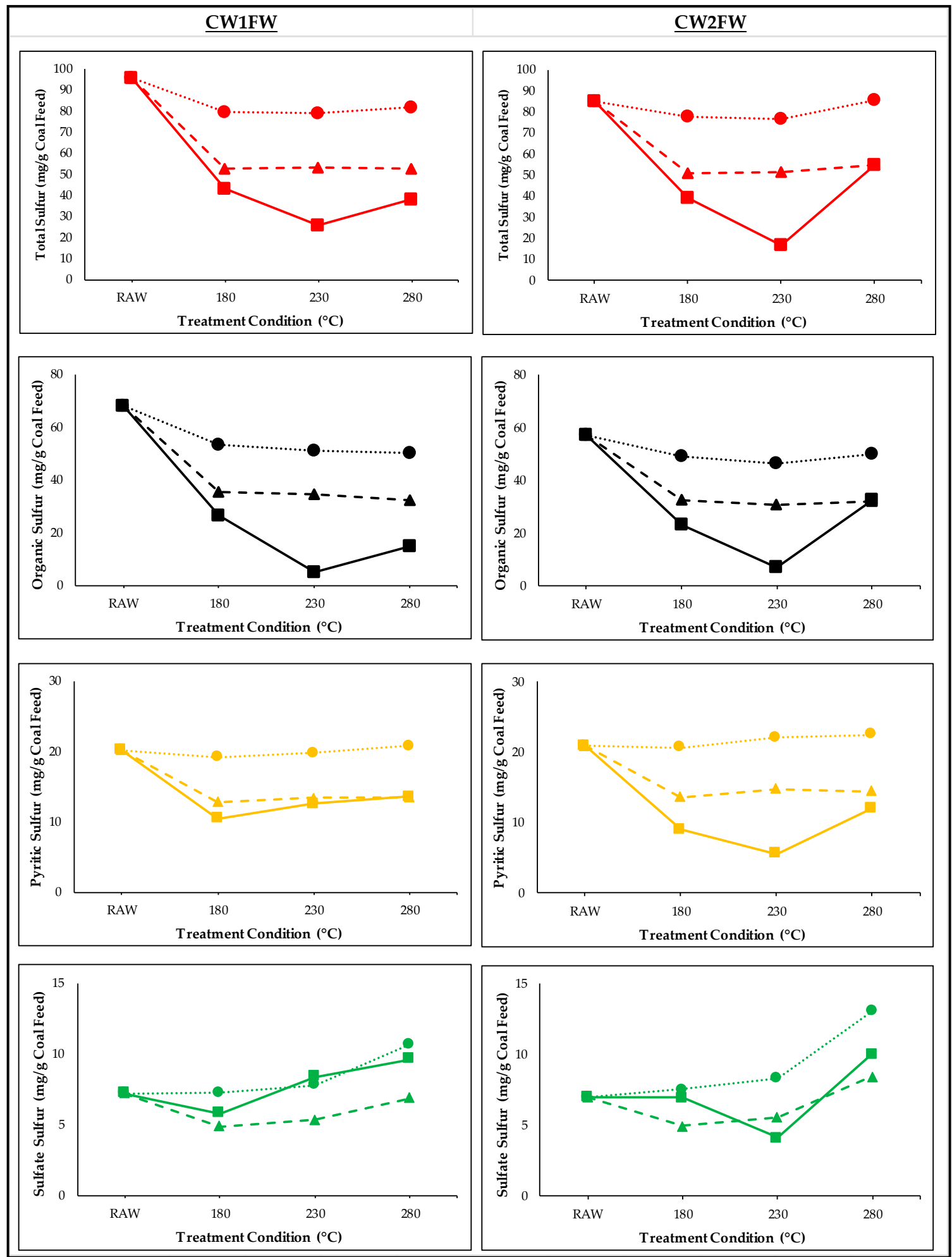

Figure 2. Absolute values of various forms of sulfur per coal feed under the Co-HTC treatment. The red, black, yellow, and green colors represent the total, organic, pyritic, and sulfate sulfur, respectively. The dotted line represents the $\mathrm{CW}$, while the dashed and solid lines indicate the theoretically calculated and experimentally measured values, respectively. 


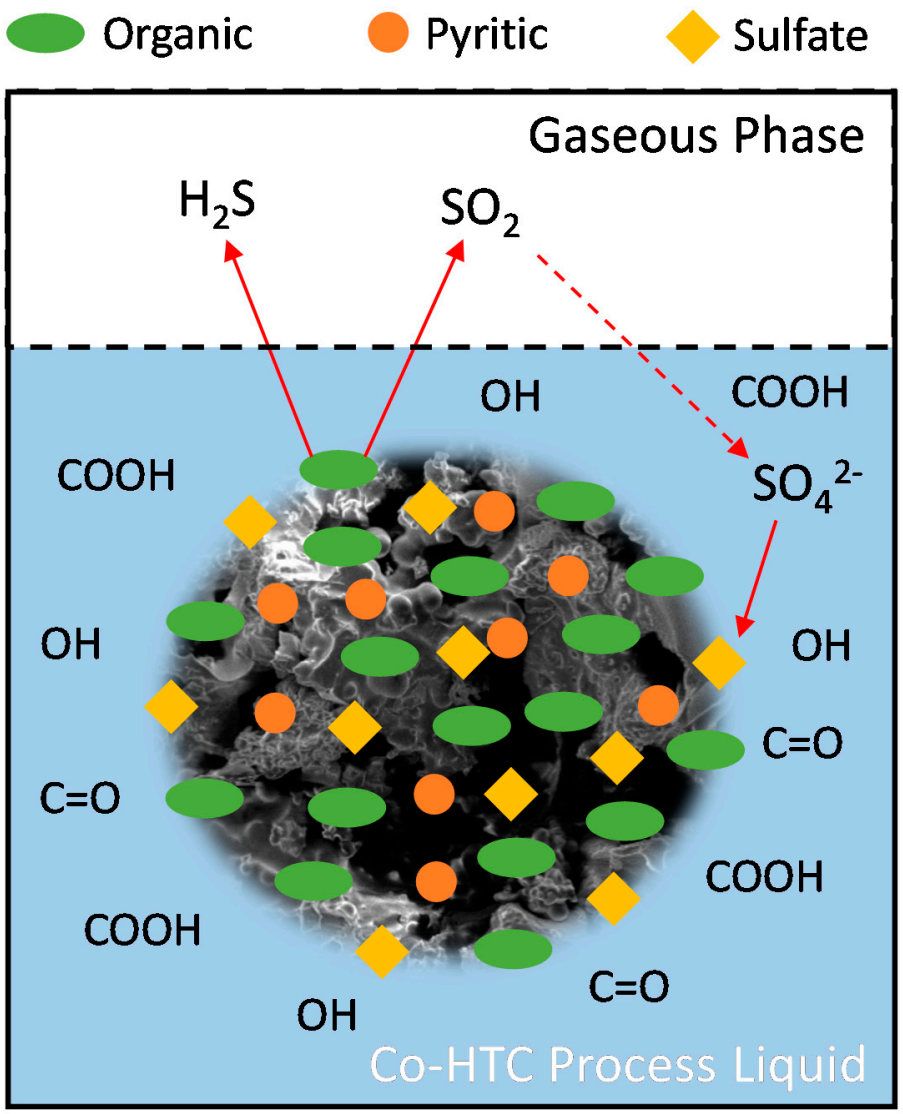

Figure 3. Proposed sulfur transformation mechanism during the Co-HTC of FW and CW.

\section{Conclusions}

This study assumed three different sulfur forms—sulfate, pyritic, and organic sulfurto be present in the $\mathrm{CW}$ and evaluated their transformation process during Co-HTC with FW. Results showed that the Co-HTC process has more significant effect on sulfur transformation compared to the HTC process. The acidic medium created due to the presence of FW in the Co-HTC process influenced the rapid transformation of sulfur. The organic sulfur transformed into sulfate sulfur, which, in turn, decreased its concentration with the increase in Co-HTC temperature up to $230^{\circ} \mathrm{C}$. However, the presence of all forms of sulfur increased with a further increase in Co-HTC temperature (i.e., $280^{\circ} \mathrm{C}$ ). These transformations may increase the emission of $\mathrm{H}_{2} \mathrm{~S}$ and decrease $\mathrm{SO}_{2}$ emission while using these hydrochars as solid fuel.

Author Contributions: Conceptualization, P.S., S.M. and M.T.R.; methodology, P.S., S.M. and N.S.; formal analysis, P.S. and S.M.; investigation, P.S., N.S. and M.T.R.; writing—original draft preparation, P.S., S.M. and N.S.; writing-review and editing, N.S., P.S. and M.T.R. All authors have read and agreed to the published version of the manuscript.

Funding: This research was funded by the National Science Foundation (Grant No. 1856058) and Ohio Coal Development Office (OCDO R-17-05).

Acknowledgments: The authors acknowledge the assistance of Akbar Saba and Benjamin Vancouver for their support in performing Co-HTC experiments. The authors also acknowledge Kyle McGaughy and Joseph Holiday for their assistance in analytical works. The authors acknowledge the support from YS Precision Stamping for their assistance in quality analysis.

Conflicts of Interest: The authors declare no conflict of interest. 


\section{References}

1. Saba, A.; Saha, P.; Reza, M.T. Co-Hydrothermal Carbonization of coal-biomass blend: Influence of temperature on solid fuel properties. Fuel Process. Technol. 2017, 167, 711-720. [CrossRef]

2. Saqib, N.U.; Sarmah, A.K.; Baroutian, S. Effect of temperature on the fuel properties of food waste and coal blend treated under co-hydrothermal carbonization. Waste Manag. 2019, 89, 236-246. [CrossRef]

3. Mazumder, S.; Saha, P.; Reza, M.T. Co-hydrothermal carbonization of coal waste and food waste: Fuel characteristics. Biomass Convers. Biorefinery 2020, 1-11. [CrossRef]

4. Mazumder, S.; Saha, P.; McGaughy, K.; Saba, A.; Reza, M.T. Technoeconomic analysis of co-hydrothermal carbonization of coal waste and food waste. Biomass Convers. Biorefinery 2020, 1-11. [CrossRef]

5. Calkins, W.H. The chemical forms of sulfur in coal: A review. Fuel 1994, 73, 475-484. [CrossRef]

6. Meng, N.; Jiang, D.; Liu, Y.; Gao, Z.; Cao, Y.; Zhang, J.; Gu, J.; Han, Y. Sulfur transformation in coal during supercritical water gasification. Fuel 2016, 186, 394-404. [CrossRef]

7. Zhong, P.; Huang, J.; Wu, H.; Zeng, W. Existing forms and transformation of S-functional groups of sewage sludge of different seasons by using XPS method. In Proceedings of the 2018 7th International Conference on Energy, Environment and Sustainable Development (ICEESD 2018), Shenzhen, China, 30-31 March 2018; Atlantis Press: Paris, France, 2018; pp. $1814-1818$.

8. Valluri, S.; Kawatra, S.K. Simultaneous removal of $\mathrm{CO}_{2}$, $\mathrm{NOx}$ and $\mathrm{SOx}$ using single stage absorption column. J. Environ. Sci. 2021, 103, 279-287. [CrossRef]

9. Stokie, D.; Verma, P.; Kumfer, B.M.; Yablonsky, G.; Suresh, A.K.; Axelbaum, R.L. Pilot-scale testing of direct contact cooler for the removal of SOx and NOx from the flue gas of pressurized oxy-coal combustion. Chem. Eng. J. 2021, 414, 128757. [CrossRef]

10. Xu, Y.; Liu, Y.; Bu, Y.; Chen, M.; Wang, L. Review on the ionic liquids affecting the desulfurization of coal by chemical agents. J. Clean. Prod. 2021, 284, 124788. [CrossRef]

11. Timpe, R.; Mann, M.; Pavlish, J.; Louie, P. Organic sulfur and hap removal from coal using hydrothermal treatment. Fuel Process. Technol. 2001, 73, 127-141. [CrossRef]

12. Favas, G.; Jackson, W.R. Hydrothermal dewatering of lower rank coals. 2. Effects of coal characteristics for a range of Australian and international coals. Fuel 2003, 82, 59-69. [CrossRef]

13. Saha, N.; McGaughy, K.; Reza, M.T. Elucidating hydrochar morphology and oxygen functionality change with hydrothermal treatment temperature ranging from subcritical to supercritical conditions. J. Anal. Appl. Pyrolysis 2020, 152, 104965. [CrossRef]

14. ASTM, D2492-02, Standard Test Method for Forms of Sulfur in Coal; ASTM International: West Conshohocken, PA, USA, 2002.

15. Wu, J.; Liu, J.; Yuan, S.; Zhang, X.; Liu, Y.; Wang, Z.; Zhou, J. Sulfur transformation during hydrothermal dewatering of low rank coal. Energy Fuels 2015, 29, 6586-6592. [CrossRef]

16. Huang, R.; Tang, Y.; Luo, L. Thermochemistry of sulfur during pyrolysis and hydrothermal carbonization of sewage sludges Waste Manag. 2021, 121, 276-285. [CrossRef]

17. Wang, Z.; Zhai, Y.; Wang, T.; Peng, C.; Li, S.; Wang, B.; Liu, X.; Li, C. Effect of temperature on the sulfur fate during hydrothermal carbonization of sewage sludge. Environ. Pollut. 2020, 260, 114067. [CrossRef]

18. Wang, Z.; Li, Q.; Lin, Z.; Whiddon, R.; Qiu, K.; Kuang, M.; Cen, K. Transformation of nitrogen and sulphur impurities during hydrothermal upgrading of low quality coals. Fuel 2016, 164, 254-261. [CrossRef]

19. Alvarez, R.; Clemente, C.; Gomez-Limon, D. The influence of nitric acid oxidation of low rank coal and its impact on coal structure. Fuel 2003, 82, 2007-2015. [CrossRef]

20. Lynam, J.G.; Reza, M.T.; Yan, W.; Vásquez, V.R.; Coronella, C.J. Hydrothermal carbonization of various lignocellulosic biomass. Biomass Convers. Biorefinery 2015, 5, 173-181. [CrossRef]

21. Li, P.-S.; Hu, Y.; Yu, W.; Yue, Y.-N.; Xu, Q.; Hu, S.; Hu, N.-S.; Yang, J. Investigation of sulfur forms and transformation during the co-combustion of sewage sludge and coal using X-ray photoelectron spectroscopy. J. Hazard. Mater. 2009, 167, 1126-1132. [CrossRef]

22. Chen, Y.; Zhao, N.; Wu, Y.; Wu, K.; Wu, X.; Liu, J.; Yang, M. Distributions of organic compounds to the products from hydrothermal liquefaction of microalgae. Environ. Prog. Sustain. Energy 2017, 36, 259-268. [CrossRef]

23. Lin, Y.; Ma, X.; Peng, X.; Hu, S.; Yu, Z.; Fang, S. Effect of hydrothermal carbonization temperature on combustion behavior of hydrochar fuel from paper sludge. Appl. Therm. Eng. 2015, 91, 574-582. [CrossRef]

24. Zhuang, X.; Zhan, H.; Huang, Y.; Song, Y.; Yin, X.; Wu, C. Denitrification and desulphurization of industrial biowastes via hydrothermal modification. Bioresour. Technol. 2018, 254, 121-129. [CrossRef]

25. Gryglewicz, G.; Jasieńko, S. The behaviour of sulphur forms during pyrolysis of low-rank coal. Fuel 1992, 71, 1225-1229. [CrossRef]

26. Pels, J.R.; Kapteijn, F.; Moulijn, J.A.; Zhu, Q.; Thomas, K.M. Evolution of nitrogen functionalities in carbonaceous materials during pyrolysis. Carbon 1995, 33, 1641-1653. [CrossRef]

27. Kelemen, S.R.; Vaughn, S.N.; Gorbaty, M.L.; Kwiatek, P.J. Transformation kinetics of organic sulphur forms in Argonne Premium coals during pyrolysis. Fuel 1993, 72, 645-653. [CrossRef]

28. ToolBox, E. Solubility of Gases in Water; 2008. Available online: https:/ /www.engineeringtoolbox.com/gases-solubility-waterd_1148.html (accessed on 8 March 2012).

29. Saha, N.; Saba, A.; Reza, M.T. Effect of hydrothermal carbonization temperature on pH, dissociation constants, and acidic functional groups on hydrochar from cellulose and wood. J. Anal. Appl. Pyrolysis 2019, 137, 138-145. [CrossRef] 